\title{
Influence of Pulsed Exposure Strategies on Overhang Structures in Powder Bed Fusion of Ti6Al4V Using Laser Beam
}

\author{
Jonas Grünewald ${ }^{1, *(D)}$, Pirmin Clarkson ${ }^{1,2} \mathbb{D}$, Ryan Salveson ${ }^{2}$, Georg Fey ${ }^{2}$ and Katrin Wudy ${ }^{1}$ \\ 1 Professorship of Laser-based Additive Manufacturing, Department of Mechanical Engineering, School of \\ Engineering \& Design, Technical University of Munich, Boltzmannstraße 15, 85748 Garching, Germany; \\ pirmin.clarkson@tum.de (P.C.); katrin.wudy@tum.de (K.W.) \\ 2 AMCM GmbH, Petersbrunner Straße 1b, 82319 Starnberg, Germany; ryan.salveson@amcm.com (R.S.); \\ georg.fey@amcm.com (G.F.) \\ * Correspondence: jonas.gruenewald@tum.de
}

Citation: Grünewald, J.; Clarkson, P.; Salveson, R.; Fey, G.; Wudy, K. Influence of Pulsed Exposure Strategies on Overhang Structures in Powder Bed Fusion of Ti6Al4V Using Laser Beam. Metals 2021, 11, 1125. https://doi.org/10.3390/ met11071125

Academic Editor: Aleksander Lisiecki

Received: 21 June 2021

Accepted: 12 July 2021

Published: 15 July 2021

Publisher's Note: MDPI stays neutral with regard to jurisdictional claims in published maps and institutional affiliations.

Copyright: (c) 2021 by the authors. Licensee MDPI, Basel, Switzerland. This article is an open access article distributed under the terms and conditions of the Creative Commons Attribution (CC BY) license (https:// creativecommons.org/licenses/by/ $4.0 /)$.

\begin{abstract}
Manufacturing structures with low overhang angles without support structures is a major challenge in powder bed fusion of metals using laser beam (PBF-LB/M). In the present work, various test specimens and parameter sets with continuous wave $(\mathrm{cw})$ and pulsed exposure are used to investigate whether a reduction of downskin roughness and overhang angle can be achieved in PBF-LB/M of Ti6Al4V. Starting from cw exposure, the limits of overhang angle and surface roughness at the downskin surface are investigated as a reference. Subsequently, the influence of laser power, scanning speed, and hatch distance with fixed pulse duration $\left(\tau_{\text {pulse }}=25 \mu \mathrm{s}\right)$ and repetition rate $\left(v_{\text {rep }}=20 \mathrm{kHz}\right)$ on surface roughness $R_{a}$ is investigated. Pulsed exposure strategies enable the manufacturing of flatter overhang angles $\left(\leq 20^{\circ}\right.$ instead of $\left.\geq 25^{\circ}\right)$. Furthermore, a correlation between the introduced volume energy density and the downskin roughness can be observed for pulsed exposure. As the reduction in volume energy density causes an increase in porosity, the combination of pulsed downskin exposure and commercial $\mathrm{cw}$ infill exposure is investigated. The larger the gap in volume energy density between the infill area and downskin area, the more challenging it is combining the two parameter sets. By combining cw infill and pulsed downskin exposure, flatter overhang structures cannot be manufactured, and a reduction in roughness can be achieved.
\end{abstract}

Keywords: additive manufacturing; powder bed fusion of metals using laser beam; PBF-LB/M; Ti6Al4V; Ti64; power modulation; pulsed exposure; overhang structure; roughness

\section{Introduction}

In laser-based powder bed fusion of metals (PBF-LB/M), continuous wave (cw) and vector-based exposure strategies are used as a standard exposure strategy nowadays. This cw exposure with high-line intensities implies high temperature gradients as well as cooling rates in and around the melt pool, which determines the process dynamic and resulting component microstructure. In the literature, the advantages of pulsed compared with $\mathrm{cW}$ exposure have been discussed for several materials over the past decades. Different beneficial aspects were addressed using pulsed exposure in PBF-LB/M:

Minimizing thermal distortion [1];

Increasing spatial resolution for thin structures [2,3];

Tailoring microstructure $[1,3]$.

These advantageous changes result primarily from the more controlled energy input. In investigations on pulsed energy input in PBF-LB/M, low repetition rates in the field of $\mathrm{Hz}$ were applied and the aim was a reduction of top and side surface quality [4,5]. To sum up these investigations: with high repetition rates, increased overlap, and reduced scan speed, the top surface roughness is reduced, but at the same time, balling effects occur and thus side surface roughness is increased [4,5]. 
Modern fiber lasers, which are mainly used in PBF-LB/M, provide the possibly to apply fast power modulation, and can thus realize a pulsed energy input with pulse durations down to the range of microseconds and pulse repetition rates up to multiple $\mathrm{kHz}$ [6]. Recent investigations on continuous and pulsed energy input for different materials prove an increase of porosity and a decrease of dimensional accuracy for large parts [2]. If thin parts, like in lattice structures, should be manufactured, pulsed energy input shows great advantages [2]. Caprio et al. [7] have proven an increase in resolution, which goes along with a decrease in efficiency for stainless steel (316L). Laitinen et al. [8] investigated the influence of pulse duration in PBF-LB/M of stainless steel (316L). Shorter pulse durations result in narrower and shallower melt pools and, therefore, require larger overlap to produce continuous melt paths [8]. Karami et al. [3] analyzed the difference between continuous and pulsed PBF-LB/M and their effect on microstructure of Ti6Al4V lattice structures. The use of pulsed exposure strategies implies a more homogenous microstructure, and thus higher compressive mechanical properties and yield stress [3].

In addition, the use of pulsed energy input allows a tailoring of the resulting microstructure, demonstrated in [1] for AlSi12 and AlSi10Mg, in [9] for AlSi10Mg, and in [10] for IN738LC. Biffi et al. [9] investigated for AlSi10Mg a slightly finer microstructure using pulsed wave laser, while the melt pool track is larger for the continuous wave mode, which leads to higher mechanical properties.

The focus of the investigation was mostly on the analysis of the microstructure, the porosity, or the resolution when using pulsed exposure in the PBF-LB/M. The investigations presented aim at the manufacturing of flatter overhang structures in the PBF-LB/M. Overhang structures are especially challenging in PBF-LB/M because of heat accumulation and consequent distortion incurred [11]. In order to eliminate distortions, external support structures are usually used to reinforce the overhang structure during the PBF-LB/M process. The use of support structures leads to time-consuming post-processing. Investigations from Calignano [12] show that overhang structures of AlSi10Mg and Ti6Al4V up to an angle of $30^{\circ}$ can be manufactured, although the surface roughness is negatively affected. Optimized support geometry leads to an improvement of part quality [12]. According to Han et al. [11], the melt pool in the dross zone is larger compared with the zone where the part is supported by underlying layers, which is caused by the lower thermal conductivity of the powder bed, and leads to higher distortion. Therefore, Han et al. [11] suggest an increased surface contact area between the part and the support structures to significantly reduce the distortion. Chen et al. [13] investigated the roughness on downskin surfaces in Ti6Al4V for angles $\geq 40^{\circ}$; the roughnesses became larger with decreasing overhang angles. For overhang angles of $40^{\circ}$, roughnesses of $R_{a} \geq 40 \mu \mathrm{m}$ could be achieved.

It is hardly possible or impractical to avoid overhang structures in additive manufacturing. The support structures required for this in PBF-LB/M have to be removed with great effort. From an AM perspective, therefore, avoiding support structures for overhang structures is favorable as this eliminates the need for time-consuming post-processing. The state-of-the-art shows quite well that overhang structures tend to distortion owing to an unbalanced thermal budget. Investigation into the use of pulsed exposure strategies leads to control of thermal budget, which leads to the following question: How flat can overhang structures be manufactured without additional support structures by using pulsed energy input in PBF-LB/M?

Therefore, the objective of this study is to extend the limits of overhang angles with reduced roughness of downskin surfaces by reducing heat accumulated in the process zone through pulsed exposure strategies. Because a reduction in introduced energy implies an increase in porosity [14], double exposures are tested to reduce porosity. Finally, selected pulsed parameter sets as downskin parameter are combined with commercially available $\mathrm{cw}$ infill parameters to produce parts with the highest relative densities possible. 


\section{Theoretical Consideration}

\section{Exposure Parameters}

State-of-the-art PBF-LB/M systems use fiber lasers as a beam source, which can be power modulated at a multiple of $10 \mathrm{kHz}$. In this study, power modulation is used for pulse generation. The pulses have a rectangle-like shape with pulse peak powers $P_{\text {peak }}$ corresponding to the set laser power. There is no power superelevation, as is the case with pulsed beam sources with Q-switch or modelocking. The energy delivered per pulse $E_{\text {pulse }}$ is determined by the pulse length $\tau_{\text {pulse }}$ and the laser peak power $P_{\text {peak }}$ according to

$$
E_{\text {pulse }}=P_{\text {peak }} \cdot \tau_{\text {pulse }} \text {. }
$$

The average power $P_{\text {avg }}$ is determined according to

$$
P_{\text {avg }}=E_{\text {pulse }} \cdot v_{\text {rep }}
$$

where $v_{\text {rep }}$ is the pulse repetition rate. Two more important parameters for the process are the distance between two pulses $d_{p u l s e}$ (see Figure 1 ) and the volume energy density $E_{v}$, which describes the energy input per volume. The distance between two pulses $d_{\text {pulse }}$ is calculated as a product of the scan speed $v_{\text {scan }}$ and the laser off time

$$
d_{\text {pulse }}=v_{\text {scan }} \cdot\left(\frac{1}{v_{\text {rep }}}-\tau_{\text {pulse }}\right) .
$$

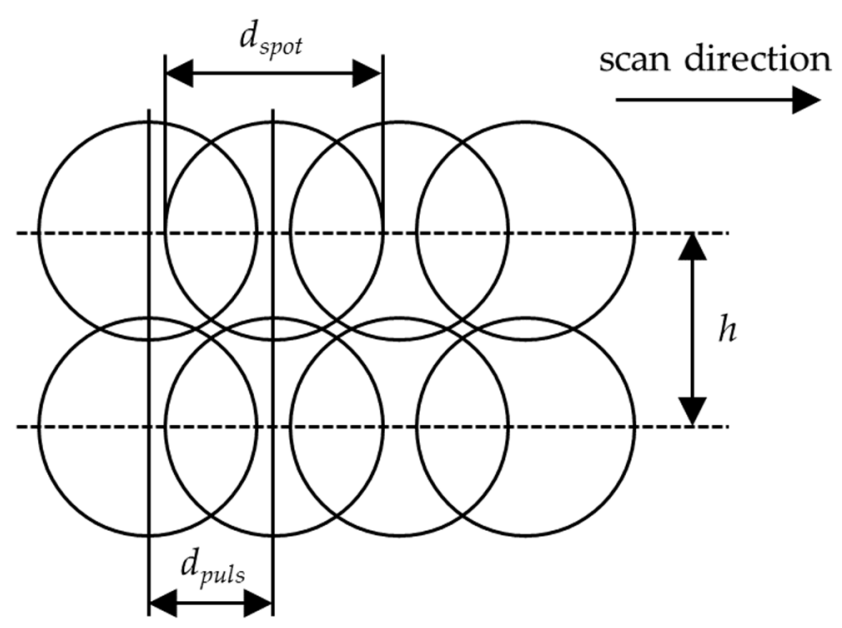

Figure 1. Schematic view of the overlapping of the laser focus points, adapted from [2].

The volume energy density $E_{v}$ is the quotient of the average power $P_{a v g}$ and the product of scan speed $v_{\text {scan }}$, hatch distance $h$, and powder layer thickness $t_{\text {powder }}$ :

$$
E_{v}=\frac{P_{a v g}}{v_{\text {scan }} \cdot h \cdot d_{\text {powder }}}=\frac{P_{\text {peak }} \cdot \tau_{\text {pulse }} \cdot v_{\text {rep }}}{v_{\text {scan }} \cdot h \cdot t_{\text {powder }}} .
$$

By combining the varied parameter, $E_{v}$ helps to compare different parameter sets. All data and equations on energies or powers in this study refer to the power emitted by the laser. The energy absorbed by the material, and thus available in the process, is always dependent on the material and the surface properties of the irradiated area.

\section{Materials and Methods}

\subsection{Feedstock Material}

In this study, Ti6Al4V is used as feedstock material. This alloy is the most widely used titanium alloy with a market share of $75-85 \%$ [15]. The reason for this is its properties such 
as good strength, ductility, fracture toughness, and corrosion and temperature resistance with a low density of $4.43 \mathrm{~g} / \mathrm{cm}^{3}$. These material properties make it particularly interesting for aerospace applications [16]. In these fields of application, the avoidance of support structures in favor of the manufacturability of complex components is in demand.

Regarding the absorption behavior of Ti6Al4V, Boley et al. [17] performed experiments on the absorption of different metal powders and substrates at a wavelength of $\lambda \approx 1 \mu \mathrm{m}$. For Ti6Al4V powder, they measured an absorption of $74 \%$ at a layer thickness of $100 \mu \mathrm{m}$. The absorption of a smooth substrate is estimated to be $39 \%$. The absorption of a rough surface (e.g., a sandblasted substrate or a layer that has already been melted) is in between, depending on the surface properties.

Ti6Al4V (EOS Titanium Ti64; [18]) powder is provided by EOS GmbH (Krailling/ Munich, Germany). The powder is produced by the gas atomization process. It has a particle size of $D_{90,3} \approx 50 \mu \mathrm{m}$. Before each process, the powder is sieved with a $63 \mu \mathrm{m}$ sieve to ensure that the particle size distribution remains constant during the tests.

\subsection{Test Specimens}

In order to show geometry limits and the influence of the introduced energy as well as the influence of an extended layer time in cw processes, the test specimens in Figure $2 \mathrm{a}, \mathrm{b}$ with overhang thicknesses of $2.5 \mathrm{~mm}$ and $10 \mathrm{~mm}$ are used. The test specimens consist of overhang structures with angles in the range of $10-40^{\circ}$, which are varied in steps of $5^{\circ}$. Flatter angles are arranged in higher z-positions to reduce interference in the manufacture of the various angles.

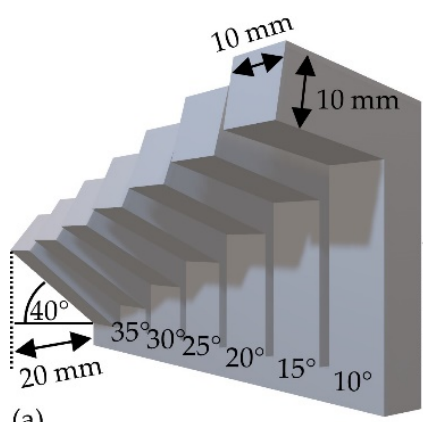

(a)
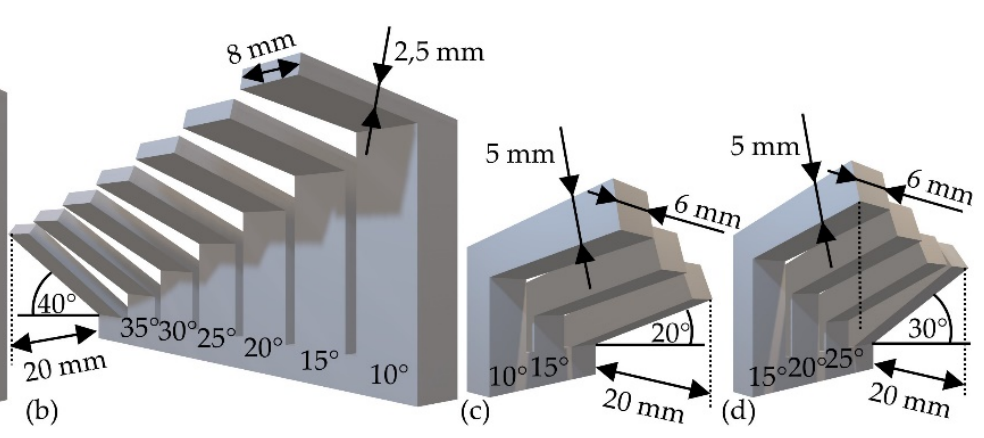

Figure 2. Schematic of the test specimens positioned on the base plate. (a) Test specimen with overhang thicknesses of $10 \mathrm{~mm}$ for cw exposure. (b) Test specimen with overhang thicknesses of $2.5 \mathrm{~mm}$ for cw exposure. (c) Test specimen with overhang thicknesses of $5 \mathrm{~mm}$ for pulsed exposure. (d) Test specimen with overhang thicknesses of $5 \mathrm{~mm}$ for combined pulsed and cw exposure.

Based on the results of the first tests, the test specimen in Figure $2 \mathrm{c}$ is used for the investigation of pulsed exposure strategies. These include adjusted cross sections and angular increments with lower angles, as overhang structures up to an angle of $25^{\circ}$ can be manufactured safely in the cw process.

For a final investigation of the combination of commercial $\mathrm{cw}$ parameters and qualified pulsed parameters, the test specimen in Figure $2 \mathrm{~d}$ is used. This test specimen is extended by angles of $25^{\circ}$ and $30^{\circ}$, whereby the angle with $10^{\circ}$ is not considered further owing to insufficient manufacturability.

\subsection{PBF-LB/M System with Optical Tomography}

The test samples were fabricated on a customized PBF-LB/M system (M290, EOS $\mathrm{GmbH}$, Krailling/Munich, Germany). The PBF-LB/M system was upgraded with a $1 \mathrm{~kW}$ fiber laser (YLR-1000-WC-Y14, IPG Photonics ${ }^{\circledR}$, Oxford, MA, USA) with a wavelength of $\lambda \approx 1070 \mathrm{~nm}$, a maximum pulse repetition rate of $v_{\text {rep }}=50 \mathrm{kHz}$, and a minimum pulse duration of $\tau_{\text {pulse }}=10 \mu \mathrm{s}$. The spot size on the base plate is $d_{\text {spot }}=80 \mu \mathrm{m}$. 
The system includes a camera-based optical tomography (OT) system (EOS GmbH, Krailling/Munich, Germany) consisting of a sCMOS camera (16-bit) placed above the process chamber and aligned to the base plate via a deflection mirror. During the manufacturing process, the OT records individual images with a narrowband filtered wavelength of $\approx 900 \mathrm{~nm}$ with exposure times of $100 \mathrm{~ms}$. The individual images are combined to form one gray-scale image per slice. The signal qualitatively estimates the process temperature via the thermal emission at $\approx 900 \mathrm{~nm}$. The data accrue as 16-bit images and are evaluated by averaging the detected data in desired areas and normalizing them. The results shown include the data of exposed cross sections from different $\mathrm{z}$-coordinates. The $\mathrm{z}$-coordinates and evaluated areas are selected depending on the test specimen and overhang angles in a way that the cross-sectional area is in comparable areas of the overhang. Table 1 summarizes the $\mathrm{z}$-coordinates and areas used.

Table 1. z-coordinates and areas of evaluated optical tomography (OT) data.

\begin{tabular}{cccc}
\hline Overhang Thickness & Angles & z-Coordinate & Area in Pixels \\
\hline $5 \mathrm{~mm}$ & $20^{\circ}$ & $8.40 \mathrm{~mm}$ & $35 \times 105$ \\
$2.5 \mathrm{~mm}$ and $10 \mathrm{~mm}$ & $25^{\circ}$ & $27.12 \mathrm{~mm}$ & $36 \times 66$ and $70 \times 179$ \\
$2.5 \mathrm{~mm}$ and $10 \mathrm{~mm}$ & $30^{\circ}$ & $26.52 \mathrm{~mm}$ & $33 \times 66$ and $70 \times 170$ \\
$2.5 \mathrm{~mm}$ and $10 \mathrm{~mm}$ & $35^{\circ}$ & $21.00 \mathrm{~mm}$ & $28 \times 66$ and $70 \times 150$ \\
$2.5 \mathrm{~mm}$ and $10 \mathrm{~mm}$ & $40^{\circ}$ & $15.72 \mathrm{~mm}$ & $23 \times 66$ and $70 \times 117$ \\
\hline
\end{tabular}

\subsection{Process Parameters}

The process parameter sets used can be categorized into three different test series: $\mathrm{cW}$ exposure, single-pulsed exposure, and double-pulsed exposure. The cw exposure test series is conducted with the commercial parameter set "Ti64_SpeedM291 1.10" of EOS GmbH (Krailling/Munich, Germany). For the overhang thicknesses of $10 \mathrm{~mm}$, the layer time is additionally increased from $t_{L 10 \mathrm{~mm}} \approx 80 \mathrm{~s}$ to $t_{M L 10 \mathrm{~mm}}=260 \mathrm{~s}$. The layer time describes the time required by the PBF-LB/M for complete processing of one layer. It can be assumed that the time for heat dissipation of an exposed volume between two exposures corresponds on average to the layer time. The additional time allows a longer heat dissipation from the process zone, and thus reduces the average process temperature. The layer time of the manufacturing process with overhang thicknesses of $2.5 \mathrm{~mm}$ is $t_{L 2.5 \mathrm{~mm}} \approx 50 \mathrm{~s}$.

Besides cw exposure, all other experiments are carried out with pulsed laser radiation (single and double exposure). The investigated parameter sets of both strategies are summarized in Table 2. The experimental parameters are constant within the respective test specimen. There are no separate contour or downskin parameters. The single-pulsed exposure test series is a screening with a wide variation of laser power $P_{\text {peak }}=140 \ldots 640 \mathrm{~W}$ with $\Delta P_{\text {peak }}=100 \mathrm{~W}$ and scan speed $v_{\text {scan }}=750 \ldots 4750 \mathrm{~mm} / \mathrm{s}$ with $\Delta v_{\text {scan }}=500 \ldots 1000 \mathrm{~mm} / \mathrm{s}$ at various hatch distance of $h=40,60,80$, and $120 \mu \mathrm{m}$ (total of 54 parameter sets). The design results in volume energy densities in the range $E_{v} \approx 4 \ldots 73 \mathrm{~J} / \mathrm{mm}^{3}$. Based on the results of the single-pulsed exposure, the parameters for the double exposure test series are derived. Restricted ranges of power $P_{\text {peak }}=140 \ldots 240 \mathrm{~W}$ with $\Delta P_{\text {peak }}=20 \mathrm{~W}$ and scan speed $v_{\text {scan }}=1000 \ldots 2500 \mathrm{~mm} / \mathrm{s}$ with $\Delta v_{\text {scan }}=500 \mathrm{~mm} / \mathrm{s}$ (total of 72 parameter sets) are chosen. The hatch distance is varied with $h=40,50$, and $60 \mu \mathrm{m}$. This series is designed full factorial. Owing to the double exposure, the design results in volume energy densities of $E_{v} \approx 16 \ldots 100 \mathrm{~J} / \mathrm{mm}^{3}$. The energy actually absorbed and thus available in the process is lower owing to the lower absorption of the already melted layer. For this reason, the volume energy densities between single and double exposure are not directly comparable. 
Table 2. Summarized pulsed process parameter sets.

\begin{tabular}{|c|c|c|c|c|c|c|}
\hline $\begin{array}{l}\text { Hatch Distance } \\
\qquad h \text { in } \mu \mathrm{m}\end{array}$ & $\begin{array}{l}\text { Peak Power } \\
P_{\text {peak }} \text { in W }\end{array}$ & $\begin{array}{c}\text { Scanning Speed } \\
v_{\text {scan }} \text { in } \mathrm{mm} / \mathrm{s}\end{array}$ & $\begin{array}{c}\text { Powder Layer Thickness } \\
t_{\text {powder }} \text { in } \mu \mathrm{m}\end{array}$ & $\begin{array}{c}\text { Pulse Duration } \\
\tau_{p u l s e} \text { in } \mu \mathrm{s}\end{array}$ & $\begin{array}{l}\text { Pulse Repetition } \\
\text { Rate } v_{\text {rep }} \text { in } \mathrm{kHz}\end{array}$ & $\begin{array}{l}\text { Number of } \\
\text { Exposures }\end{array}$ \\
\hline 40 & 140,240 & 750 & 60 & 25 & 20 & 1 \\
\hline 40 & $\begin{array}{c}140,240,340 \\
440\end{array}$ & 1250,2250 & 60 & 25 & 20 & 1 \\
\hline 60 & $\begin{array}{l}140,240,340 \\
440,540,640\end{array}$ & $\begin{array}{c}2250,3250,4250, \\
4750\end{array}$ & 60 & 25 & 20 & 1 \\
\hline 80 & $\begin{array}{c}140,240,340 \\
440\end{array}$ & 750,1250 & 60 & 25 & 20 & 1 \\
\hline 120 & $\begin{array}{l}140,240,340 \\
440,540,640\end{array}$ & 750,1250 & 60 & 25 & 20 & 1 \\
\hline $40,50,60$ & $\begin{array}{l}140,160,180 \\
200,220,240\end{array}$ & $\begin{array}{c}1000,1500,2000, \\
2500\end{array}$ & 60 & 25 & 20 & 2 \\
\hline
\end{tabular}

All test samples are built with a pulse repetition rate of $v_{\text {rep }}=20 \mathrm{kHz}$, a pulse duration of $\tau_{\text {pulse }}=25 \mu \mathrm{s}$, and a powder layer thickness of $t_{\text {powder }}=60 \mu \mathrm{m}$.

The reduction of volume energy density leads to increased porosities [14]. However, for most applications, it is necessary that components have a high density to ensure high quality and good mechanical properties [19]. Therefore, three parameter sets with low downskin roughnesses and various powers, hatches, scan speeds, and volume energy densities are combined with the commercial cw infill parameter set "Ti64_SpeedM291 1.10" qualified to produce high densities. The parameter sets Downskin 1 and 2 are taken from the double pulsed exposure test series. Downskin 3 is based on the single-pulsed exposure test series, but receives an adjusted scan speed. With these downskin parameter sets (shown in Table 3), single and double exposures and the variation of downskin thickness are investigated. The areas to which the various parameter sets are assigned are shown schematically in Figure 3.

Table 3. Summarized process parameters for the combination of $\mathrm{cw}$ and pulsed exposure.

\begin{tabular}{|c|c|c|c|c|c|c|c|}
\hline Name & $\begin{array}{c}\text { Hatch } \\
\text { Distance } h \text { in } \\
\mu \mathrm{m}\end{array}$ & $\begin{array}{c}\text { Peak Power } \\
P_{\text {peak }} \text { in } \mathrm{W}\end{array}$ & $\begin{array}{c}\text { Scanning } \\
\text { Speed } v_{\text {scan }} \text { in } \\
\mathrm{mm} / \mathrm{s}\end{array}$ & $\begin{array}{c}\text { Powder Layer } \\
\text { Thickness } t_{\text {powder }} \text { in } \\
\mu \mathrm{m}\end{array}$ & $\begin{array}{c}\text { Pulse Duration } \\
\tau_{p u l s e} \text { in } \mu \mathrm{s}\end{array}$ & $\begin{array}{l}\text { Pulse Repetition } \\
\text { Rate } v_{r e p} \text { in } \mathbf{k H z}\end{array}$ & $\begin{array}{c}\text { Volume Energy } \\
\text { Density } E_{v} \text { in } \mathrm{J} / \mathrm{mm}^{3}\end{array}$ \\
\hline Downskin 1 & 40 & 140 & 2500 & 60 & 25 & 20 & 12 \\
\hline Downskin 2 & 60 & 240 & 2000 & 60 & 25 & 20 & 17 \\
\hline Downskin 3 & 120 & 340 & 850 & 60 & 25 & 20 & 28 \\
\hline Infill & \multicolumn{3}{|c|}{ Ti64_SpeedM291 1.10} & 60 & $\mathrm{cw}$ & $\mathrm{cW}$ & 38 \\
\hline
\end{tabular}

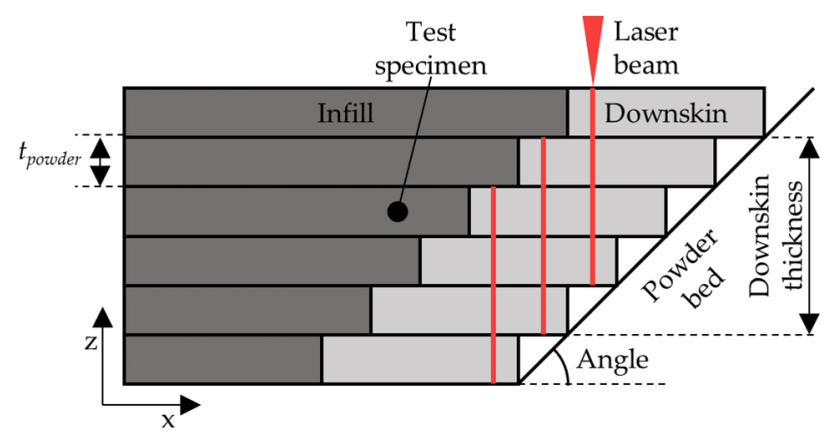

Figure 3. Schematic of parameter combination in the infill and downskin area.

\subsection{Build Job Design}

The build job design for the different test specimens from Figure 1 is shown in Figure 4. In accordance with VDI 3405 Part 2 [20], the test specimens are placed at an azimuth angle of $45^{\circ}$ to the coating and gas flow direction with the open angle ends oriented in the coating direction. This arrangement prevents protruding test specimens from being approached head-on by the coater blade and increases process robustness. The twisted arrangement prevents scan paths in the direction of the shielding gas flow during contour runs or runs 
parallel to the contour. In this way, undesirable interactions between discharged process emissions and the laser radiation are reduced.

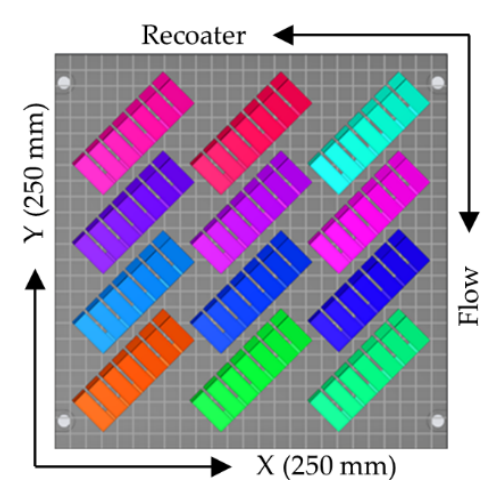

(a)

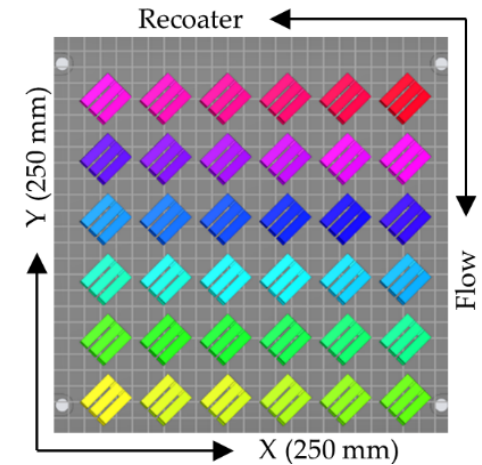

(b)

Figure 4. Design of build jobs with test specimens: cw exposure (a) and pulsed exposure (b).

\subsection{Component Properties}

To assess the manufacturability of flat overhang structures, the roughness of the downskin areas of the test specimens is measured. As very large roughness values are expected at the downskin surfaces owing to the geometry and the process, the specimens are declared not manufacturable from a roughness $R_{a}>150 \mu \mathrm{m}$, which is about twice as high as the reference values shown later. Porosity analyses are performed for selected parameter sets, because the focus of the optimization is on the reduction of roughness.

\subsubsection{Roughness Measurement}

A 3D profilometer (Keyence VR-3200, Ōsaka, Japan) is used to measure the roughness on the downskin surfaces of the test specimens via fringe projection. By means of the fringe projection method, an unambiguous topography measurement and high resolution can be achieved [21]. In order to establish comparability with other measurements, the established arithmetic average roughness $R_{a}$ according to ISO 4287 [22] is evaluated from the raw data obtained by 31 homogeneously distributed single measurement sections of $20 \mathrm{~mm}$ in length. No low-pass filter $\lambda_{s}$ is used in the evaluation, and the high-pass cut-off wavelength is set to $\lambda_{c}=2.5 \mathrm{~mm}$.

\subsubsection{Porosity}

In order to compare the porosities of single and double exposure on one example parameter set, micrographs are created. For this purpose, the specimens are prepared in an acrylic cold mounting system, then ground with a 220 grit $\mathrm{SiC}$ foil and polished in three stages with cloths and polishing suspensions $(9 \mu \mathrm{m}, 1 \mu \mathrm{m}, 0.04 \mu \mathrm{m})$. Subsequently, the micrographs are recorded with a $5 \times$ objective and a pixel size of approximately $1.4 \mu \mathrm{m} / \mathrm{px}$.

\section{Results and Discussion}

\subsection{Continuous Exposure Strategies}

Initial tests with commercial cw process parameters show the limits of manufacturing overhang structures using $\mathrm{cw}$ parameters and the potential to reduce the roughness by reducing heat accumulation in the specimen as a reference. According to Calignano [12], manufacturing of overhang structures with angles of $30^{\circ}$ using PBF-LB/M is possible. With the commercial cw parameters in this study, structures with overhang thicknesses of $2.5 \mathrm{~mm}$ and $10 \mathrm{~mm}$ with angles up to $25^{\circ}$ can be manufactured.

Figure 5a shows that the reference test specimens with overhang thicknesses of $10 \mathrm{~mm}$ have roughnesses of $R_{a}>70 \mu \mathrm{m}$ on the downskin surface for all angles shown. The test specimens with overhang thicknesses of $2.5 \mathrm{~mm}$ exhibit, with $R_{a}<55 \mu \mathrm{m}$, significantly lower roughnesses for all angles. The extension of the layer time from 
$t_{L 10 \mathrm{~mm}} \approx 80 \mathrm{~s}$ to $t_{M L 10 \mathrm{~mm}}=260 \mathrm{~s}$ with $\Delta t_{10 \mathrm{~mm}} \approx 180 \mathrm{~s}$ in the production of the reference test specimens with overhang thicknesses of $10 \mathrm{~mm}$ also leads to a significant reduction of the roughness $R_{a}<50 \mu \mathrm{m}$ for all angles shown. These values fit well with studies by Chen et al. [13], who achieved roughnesses on downskin surfaces of $R_{a} \geq 40 \mu \mathrm{m}$ at $40^{\circ}$ angles, $R_{a} \geq 30 \mu \mathrm{m}$ at $50^{\circ}$ angles, and $R_{a} \geq 15 \mu \mathrm{m}$ at $60^{\circ}$ angles.

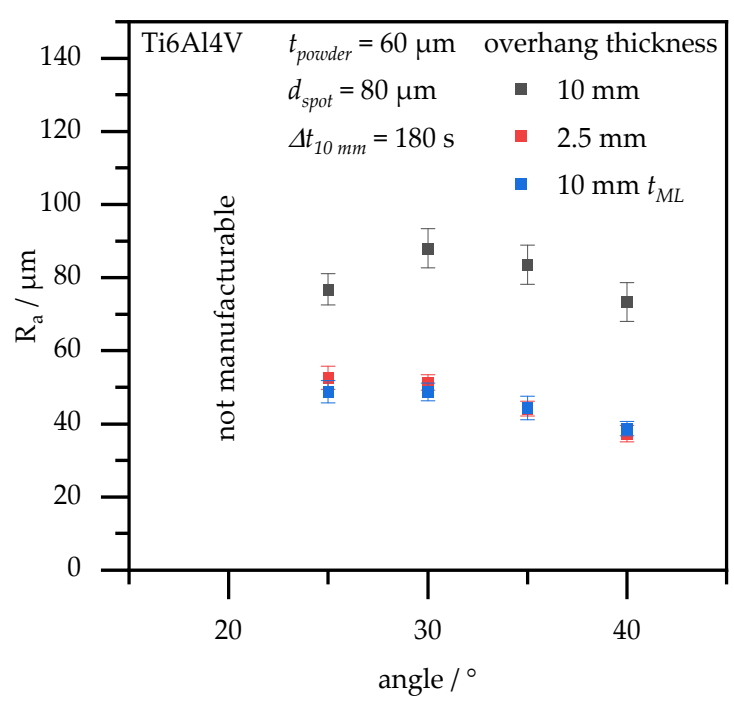

(a)

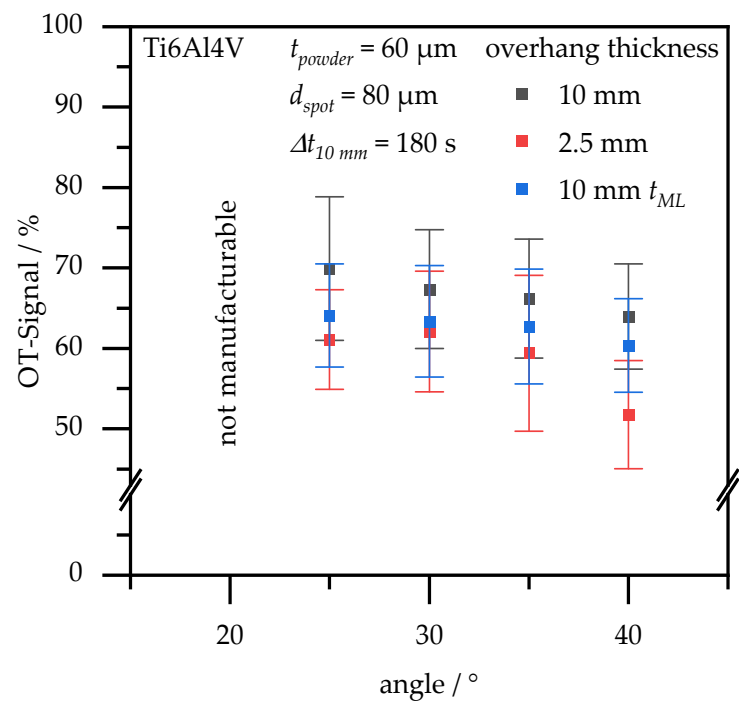

(b)

Figure 5. Measured roughnesses $R_{a}(\mathbf{a})$ and OT signal (b) with commercial cw process parameters with varying specimens, overhang angles, and layer times.

Reducing the overhang thickness from $10 \mathrm{~mm}$ to $2.5 \mathrm{~mm}$ reduces the volume and area per layer to be melted. This reduces the energy introduced into the overhang structure. Less energy introduced results in less heat accumulated in the specimen. Extending the layer time by $3 \mathrm{~min}$ for test specimens with overhang thickness of $10 \mathrm{~mm}$ enables heat to be dissipated from the processing zone into the specimen and base plate for 3 min longer, thus reducing the heat accumulated. Lower accumulated heat results in lower process temperatures, and thus a reduction of thermal radiation at $900 \mathrm{~nm}$, which can be detected by the OT system (see Figure $5 b$ ). Both adjustments in the cw exposure slightly reduce the average OT signal, confirming a reduction in the process temperature.

This lower process temperature tends to lead to lower roughness values on the overhang structures. The reasons for this can be less adhering powder particles, less melt pool dynamics at the overhang structures, as well as the formation of smaller melt pools in the dross zone as shown in [11]. The high standard deviations of the OT signals in Figure 5b indicate high melt pool dynamics, resulting in more irregular melt tracks at the downskin surface, and thus causing the comparatively high roughness values. In addition to reducing accumulated heat, reducing melt pool dynamics through pulsed exposure strategies offers the potential to reduce downskin roughness.

\subsection{Pulsed Exposure Strategies}

The pulsed exposure test series (see Section 3.4.) confirms that the reduction of the introduced volume energy density $E_{v}$ also causes a reduction of roughness even with pulsed exposure.

Figure 6 shows the results of the single-pulsed exposure test series. The measured roughness values $R_{a}$ at the downskin surfaces of $20^{\circ}$ overhang structures are presented as a function of power $P(\mathrm{a})$, scan speed $v(\mathrm{~b})$, and volume energy density $E_{v}(\mathrm{c})$ calculated according to Equation (4). For the sake of clarity, only parameter combinations with hatches $h=60,120 \mu \mathrm{m}$ are shown in Figure 6a,b. As the hatch distances $h$ are adjusted to power, 
scan speed, and volume energy density (see Section 3.4), they are not shown in a separate diagram. Figure $6 \mathrm{c}$ summarizes all tested parameter combinations. For volume energy densities $E_{v}<7 \mathrm{~J} / \mathrm{mm}^{3}$, the applied energy is not sufficient to produce adequate material cohesion. Corresponding parameter sets are thus not considered further.

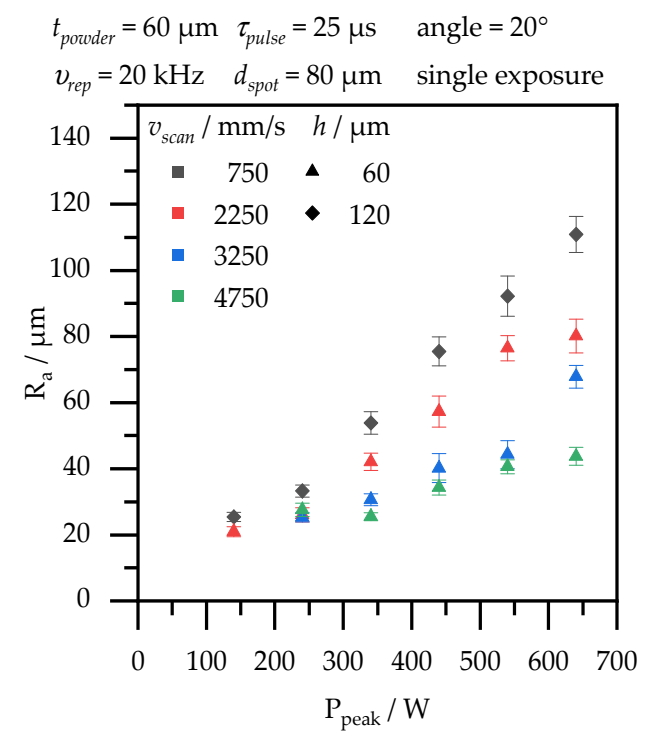

(a)

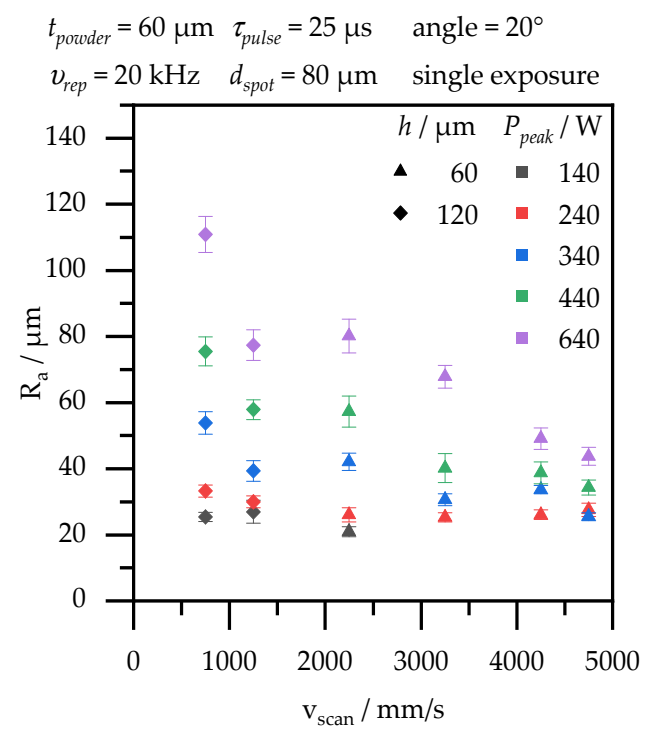

(b)

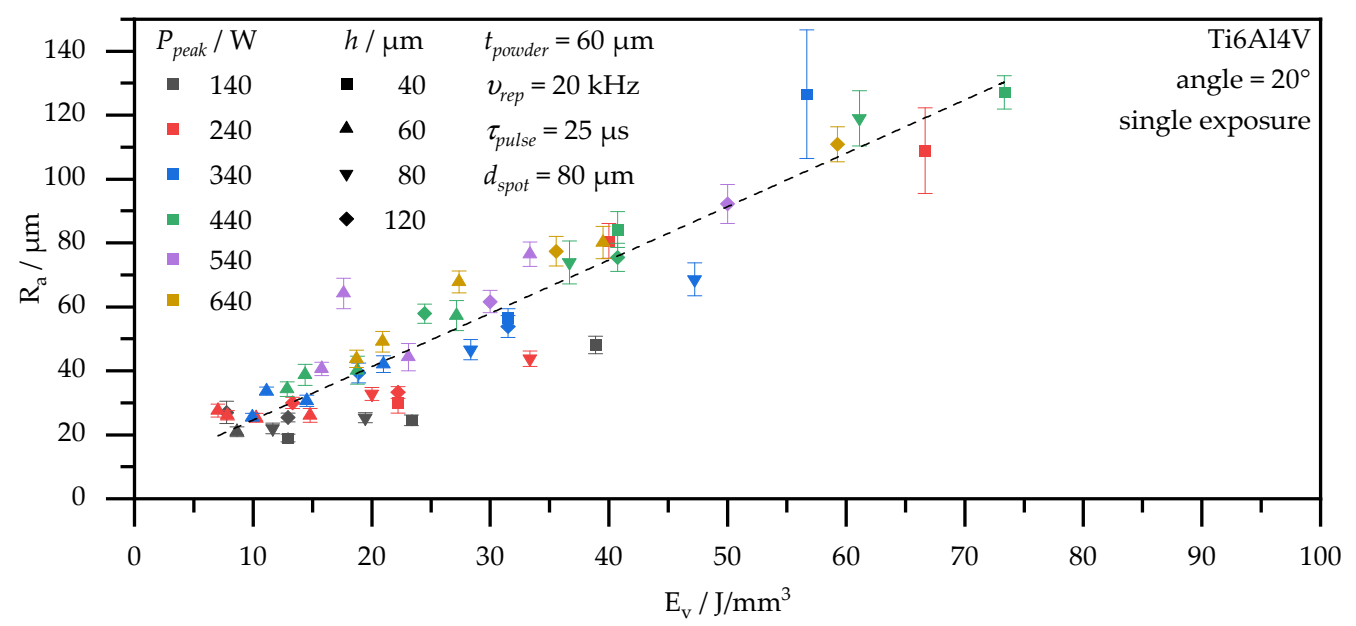

(c)

Figure 6. Measured roughnesses $R_{a}$ of $20^{\circ}$ angles with single exposure: Roughness $R_{a}$ as a function of the laser peak power $P_{\text {peak }}(\mathbf{a})$, scan speed $v_{\text {scan }}(\mathbf{b})$ and volume energy density $E_{v}(\mathbf{c})$.

Figure 6a,b show increasing roughnesses $R_{a}$ for increasing laser power $P_{\text {peak }}$ and decreasing scanning speed $v_{\text {scan }}$. Summarizing the varied and constant process parameters into the volume energy density (see Equation (4)), it can be seen in Figure 6c that volume energy densities $E_{v}$ and roughnesses $R_{a}$ are strongly correlated. High volume energy densities $E_{v}$ lead to high roughnesses $R_{a}$.

At similar volume energy densities $E_{v}$, parameter sets with low power (especially $P=140,240 \mathrm{~W}$ ) lead to low roughness values. As published by Demir et al. [2] and Laitinen et al. [8], pulsed exposures lead to narrower melt tracks owing to shorter interaction times of laser and material. This suggests that, without adjusting the hatch to $h<120 \mu \mathrm{m}$, there is an insufficient overlap of individual melt tracks. In order to ensure sufficient overlap of adjacent melt tracks, and thus enable low roughness and theoretically dense components, the hatch distances have to be in a sufficiently low range. Assuming that the distance for 
two adjacent pulses should also not be greater than a suitable hatch distance $h \leq 80 \mu \mathrm{m}$, Equation (3) shows that, for a pulse duration of $\tau_{\text {pulse }}=25 \mu$ s and a pulse repetition rate of $v_{\text {rep }}=20 \mathrm{kHz}$, a scan speed of $v_{\text {scan }}<3200 \mathrm{~mm} / \mathrm{s}$ must be used to achieve sufficient overlap between the pulses and melt tracks. Figure $6 \mathrm{~b}$ shows that the roughnesses remain constant above this scan speed (with the exception of the samples produced with the laser power $P=640 \mathrm{~W}$ ). This means that there is already a minimum of roughness. Increasing the scan speed above this value further decreases the volume energy density, potentially leading to an unnecessary increase in porosity.

Figure 7 shows the measured OT signals as a function of the volume energy density $E_{v}$. As can be seen, the introduced volume energy density and the signal delivered by OT are strongly correlated. As the volume energy density decreases, the standard deviation of the OT signal also decreases. Consequently, the introduction of lower volume energy densities $E_{v}$ lowers the average temperature in the overhang structures during pulsed processes, resulting in smoother processes and lower roughness on the downskin surfaces of the test specimens. However, the lower energy input leads to increased porosities (see Figure 8). Using the parameter set shown in Figure 8 as an example, it can be found that double exposure has the potential to reduce porosity (by $23.8 \%$ ) with increasing roughness (by $12.9 \%$ ). For these reasons, the double exposure test series is designed as described in Section 3.4.

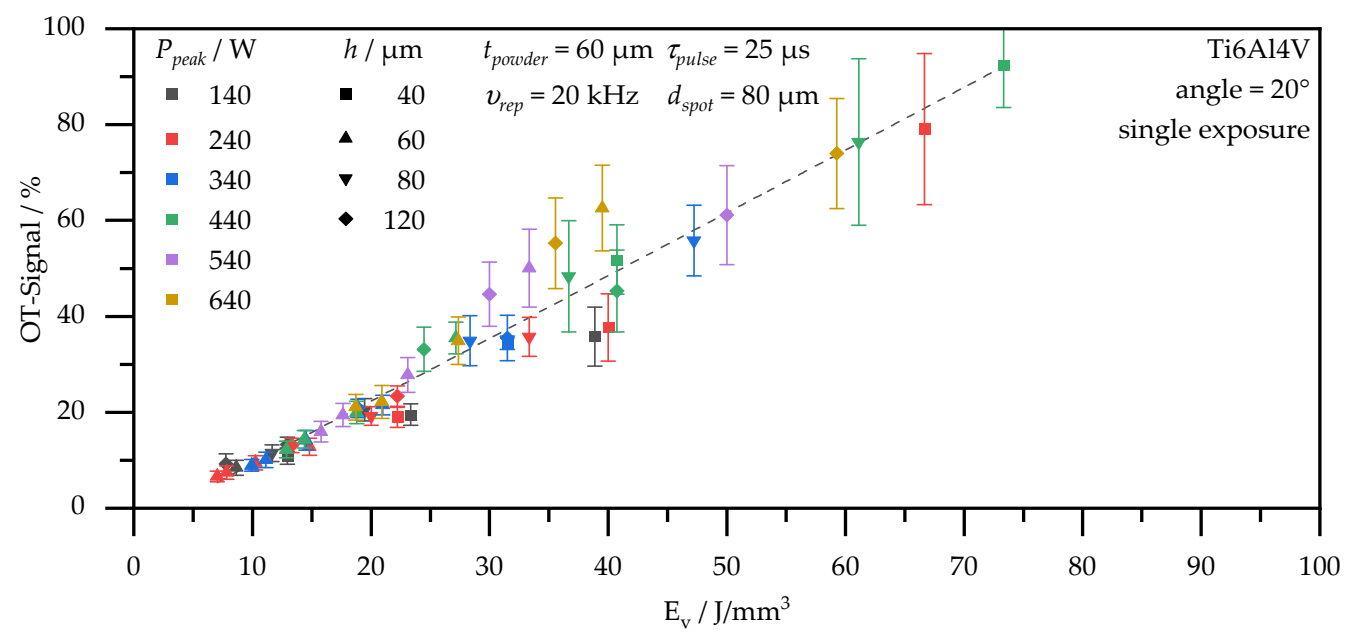

Figure 7. Measured OT signals of $20^{\circ}$ angles with broad varying powers, scan speeds, and hatch distances.

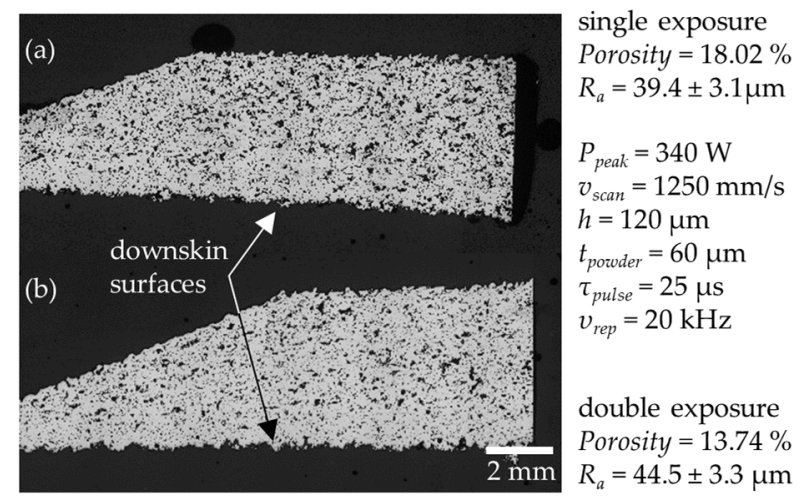

Figure 8. Comparison of porosities from single exposure (a) to double exposure (b).

Figure 9 shows the results of the double-pulsed exposure test series. The values for the volume energy density are split into two exposure passes with identical parameters. The calculated total energy introduced is thus twice as high. As already mentioned, the energy introduced is not equal to the absorbed energy actually present in the process. 


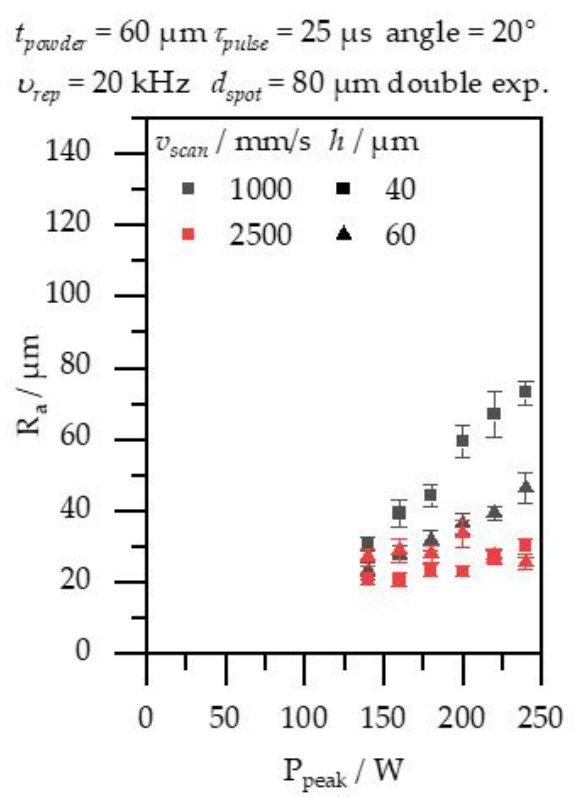

(a)

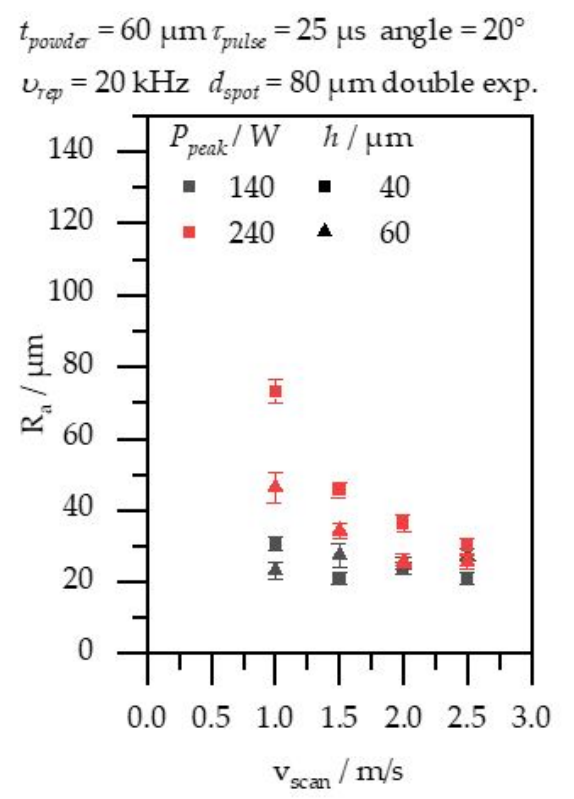

(b)

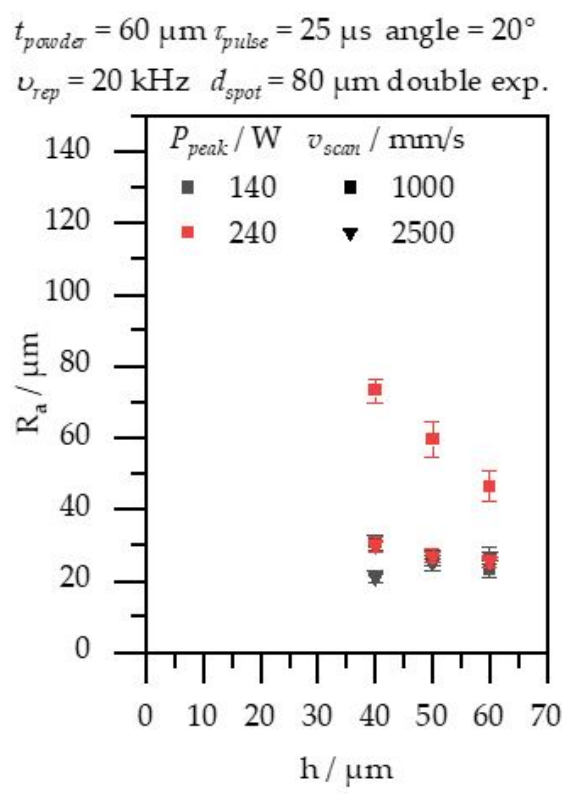

(c)

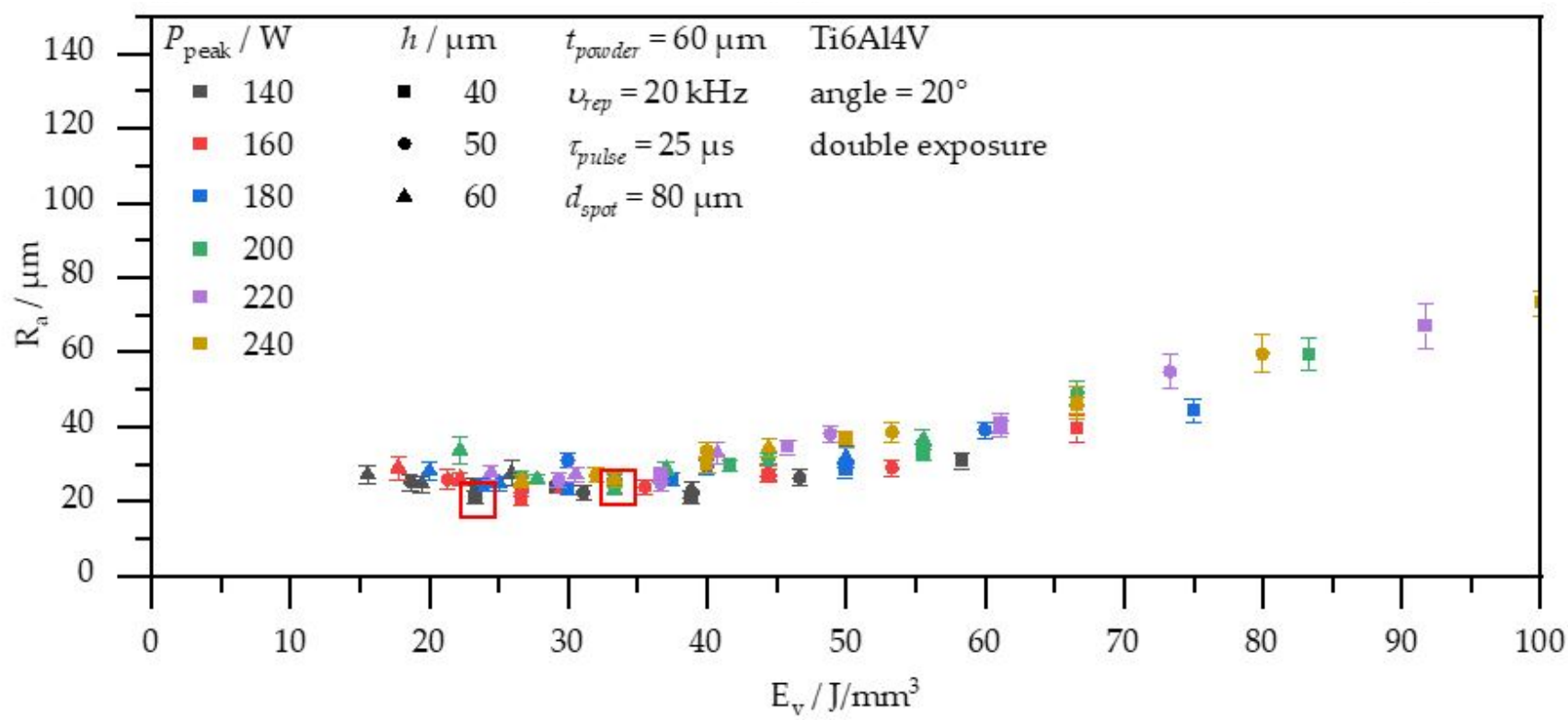

(d)

Figure 9. Measured roughnesses $R_{a}$ of $20^{\circ}$ angles with double exposure: Roughness $R_{a}$ as a function of the laser peak power $P_{\text {peak }}(\mathbf{a})$, scan speed $v_{\text {scan }}(\mathbf{b})$, hatch distance $h(\mathbf{c})$ and volume energy density $E_{v}(\mathbf{d})$.

In Figure 9, the roughnesses are plotted as a function of laser power $P_{\text {peak }}(\mathrm{a})$, scan speed $v_{\text {scan }}(\mathrm{b})$, and hatch distance $h$ (c) for two levels of the remaining parameters. Figure $9 \mathrm{~d}$ summarizes all parameter combinations as volume energy density $E_{v}$ and shows the roughness as a function of $E_{v}$. The level of roughness values $R_{a}$ is significantly lower than in the more widely spread single exposure test series, which can be explained by the lower absorbed energy owing to double exposure. Figure $9 \mathrm{a}-\mathrm{c}$ show that low powers $P_{\text {peak }}$, high scan speeds $v_{\text {scan }}$, and high hatch distances $h$ tend to lead to small downskin roughnesses $R_{a}$. Summarizing these process parameters to volume energy density $E_{v}$ confirms a correlation (see Figure $9 \mathrm{~d}$ ). It can be seen that the lowest roughnesses are achieved from volume energy densities of $E_{v} \approx 50 \mathrm{~J} / \mathrm{mm}^{3}$. A further reduction of the volume energy density does not lead to lower values for roughness $R_{a}$. The roughnesses are in the volume energy density range between $E_{v} \approx 15 \ldots 50 \mathrm{~J} / \mathrm{mm}^{3}$ at a level between $R_{a} \approx 20 \ldots 35 \mu \mathrm{m}$. Although 
double exposures contribute twice as much energy as single exposures, the results show that double exposures can achieve very low roughness values on the downskin surfaces compared with a cw process or single exposures.

For the final investigation of the combination of pulsed and continuous exposure strategies, three parameter sets with low roughnesses of different powers, scan speed, hatches, and volume energy densities are selected (see red squares in Figure 9d).

\subsection{Combination of Pulsed Downskin and Continuous Wave Infill Parameters}

When combining pulsed downskin with $\mathrm{cw}$ infill parameters (see Figure 3), the overhang structures with angles of $20^{\circ}$ cannot be manufactured. For this reason, the results of the next steeper overhang angle $\left(25^{\circ}\right)$ are presented. With parameter set Downskin 1 $\left(E_{v} \approx 12 \mathrm{~J} / \mathrm{mm}^{3}\right), 25^{\circ}$ angles are also not manufacturable (see exemplary Figure 10). Test specimens with parameter sets Downskin 2 and $3\left(E_{v} \approx 17,28 \mathrm{~J} / \mathrm{mm}^{3}\right)$ can be manufactured regardless of the downskin thickness. Figure 11 shows the roughness as a function of the downskin thickness (see Figure 3). The commercial cw parameter set $\left(E_{v} \approx 38 \mathrm{~J} / \mathrm{mm}^{3}\right)$ is shown for reference as a vertical line and at $0 \mathrm{~mm}$ downskin thickness.

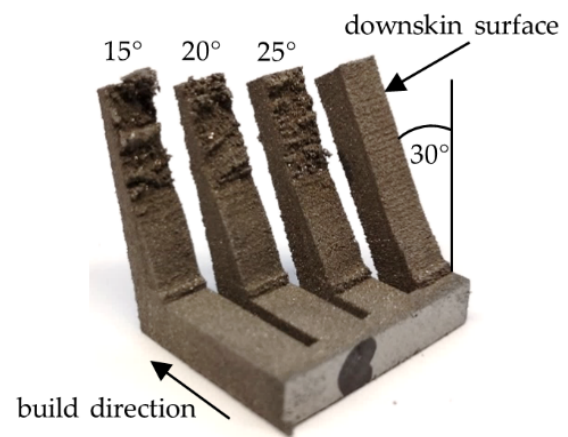

Figure 10. Photograph of test specimen with combined $\mathrm{cw}\left(E_{v} \approx 38 \mathrm{~J} / \mathrm{mm}^{3}\right)$ and pulsed $\left(E_{v} \approx 12 \mathrm{~J} / \mathrm{mm}^{3}\right)$ parameters with a downskin thickness of $2.4 \mathrm{~mm}$.

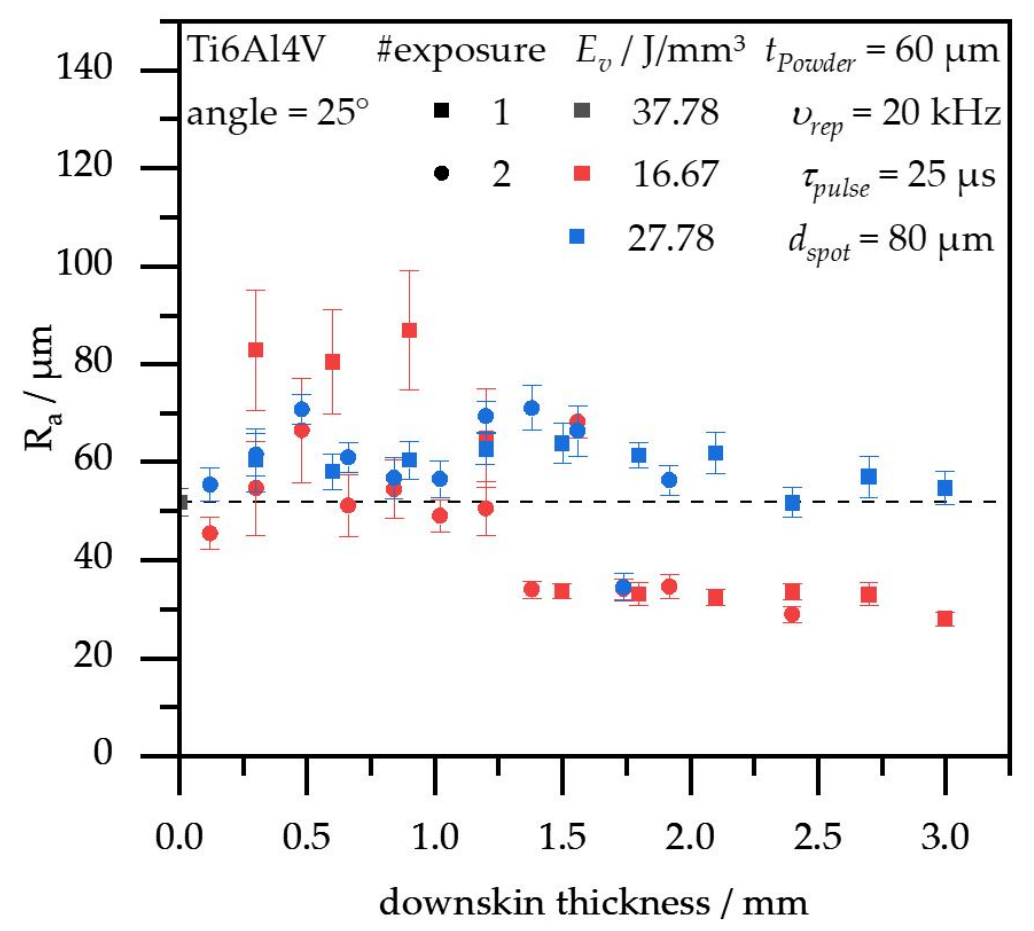

Figure 11. Measured roughnesses $R_{a}$ of $25^{\circ}$ angles with commercial cw infill parameter as a function of downskin thickness with pulsed parameters. 
As can be seen, the roughness values increase for the combination of pulsed and $\mathrm{cw}$ parameters for thin downskin areas, especially for single exposure with Downskin $2\left(E_{v} \approx 17 \mathrm{~J} / \mathrm{mm}^{3}\right)$. The roughness values for the combination of $\mathrm{cw}$ infill and pulsed downskin with Downskin $3\left(E_{v} \approx 28 \mathrm{~J} / \mathrm{mm}^{3}\right)$ remain at a consistent level above the achievable roughness of $\mathrm{cw}$ parameters without separate downskin exposure, regardless of the downskin thickness used. The roughnesses of the downskin surfaces with Downskin $2\left(E_{v} \approx 17 \mathrm{~J} / \mathrm{mm}^{3}\right)$ exceed these values up to a downskin thickness of $1.2 \mathrm{~mm}$. From a downskin thickness of $\geq 1.5 \mathrm{~mm}$, the roughness reaches its minimum with this parameter combination and falls below the roughness values for the cw exposure without a separate downskin parameter.

One possible hypothesis is that the cw infill exposure introduces energy into the material at a level at which the heat capacity and thermal conductivity of the downskin region are no longer sufficient to dissipate the heat owing to the increased porosity. As a result, the downskin area overheats, which leads to increased roughness and, in extreme cases, even reduces the manufacturability of the specimen. The larger the gap between the energy densities, the higher the porosity in the downskin area, which intensifies the effect. This hypothesis is supported by the high roughnesses in single exposures with Downskin $2\left(E_{v} \approx 17 \mathrm{~J} / \mathrm{mm}^{3}\right)$. In these specimens, the double exposure presumably reduces the porosity, so that the increase in roughness is lower. Above a certain downskin thickness (approximately $1.3 \mathrm{~mm}$ in the example shown), the temperature at the interface between the powder bed and the downskin surface is no longer critical for roughness increase. As temperature increases occur in deeper layers, it cannot be detected with the existing system technology.

\section{Conclusions}

In this study, the influence of pulsed exposure strategies $\left(\tau_{\text {pulse }}=25 \mu \mathrm{s}, v_{\text {rep }}=20 \mathrm{kHz}\right)$ on manufacturing of flat overhang structures and the roughness of corresponding downskin surfaces in powder bed fusion of Ti6Al4V using laser beam was investigated. Initially, it was found that a reduction in accumulated heat during $\mathrm{cw}$ exposure has the potential to reduce downskin surface roughness. The use of pulsed exposure strategies instead of cw also leads to reduced accumulated heat.

The results of this investigation can be summarized in the following key takeaways:

- Pulsed exposure strategies with reduced volume energy densities enable manufacturing of flatter overhang structures down to $<20^{\circ}$ (pulsed) instead of $25^{\circ}(\mathrm{cw})$.

- In addition, pulsed exposure strategies lead to a reduction in roughness at the downskin surfaces down to $\mathrm{R}_{\mathrm{a}} \approx 20 \mu \mathrm{m}$ (pulsed) instead of $\mathrm{R}_{\mathrm{a}} \approx 50 \mu \mathrm{m}$ (cw).

- When combining $\mathrm{cw}$ infill and pulsed downskin, heat accumulation and thickness of the downskin area must be considered to enable a decrease in roughness. A reduction of the overhang angle could not be shown owing to the high energy introduced in the infill.

In order to achieve low overhang angles and low downskin roughness at high component densities, a further research approach could be to increase the volume energy density from the downskin surface in a graded manner. Thus, the gap in energy densities and porosities between downskin and infill could be reduced.

In this study, pulse repetition rates and pulse durations were kept constant with $v_{\text {rep }}=20 \mathrm{kHz}$ and $\tau_{\text {pulse }}=25 \mu \mathrm{s}$. The pulse durations, repetition rates, and their combination have an influence on the process and the process result [8]. Studies with varying pulse durations and repetition rates should thus be the subject of further investigations.

This study demonstrates the enormous potential that the use of pulsed exposure strategies offers in reducing and avoiding support structures.

Author Contributions: Conceptualization, J.G., R.S., and G.F.; methodology, J.G., P.C., and R.S.; validation, J.G. and P.C.; formal analysis, J.G. and P.C.; investigation, P.C.; resources, G.F.; data curation, J.G.; writing—original draft preparation, J.G.; writing-review \& editing, J.G. and K.W.; 
visualization, J.G. and P.C.; supervision, G.F. and K.W.; project administration, J.G. and R.S.; funding acquisition, no additional/external funding. All authors have read and agreed to the published version of the manuscript.

Funding: This research received no external funding.

Data Availability Statement: The data presented in this study are available in the article.

Acknowledgments: This study was carried out in close cooperation with AMCM GmbH (an EOS group company). We thank AMCM for providing their infrastructure and materials as well as the great cooperation.

Conflicts of Interest: The authors declare no conflict of interest.

\section{References}

1. Chou, R.; Milligan, J.; Paliwal, M.; Brochu, M. Additive Manufacturing of Al-12Si Alloy Via Pulsed Selective Laser Melting. JOM 2015, 67, 590-596. [CrossRef]

2. Demir, A.G.; Colombo, P.; Previtali, B. From pulsed to continuous wave emission in SLM with contemporary fiber laser sources: Effect of temporal and spatial pulse overlap in part quality. Int. J. Adv. Manuf. Technol. 2017, 91, 2701-2714. [CrossRef]

3. Karami, K.; Blok, A.; Weber, L.; Ahmadi, S.M.; Petrov, R.; Nikolic, K.; Borisov, E.V.; Leeflang, S.; Ayas, C.; Zadpoor, A.A.; et al. Continuous and pulsed selective laser melting of Ti6Al4V lattice structures: Effect of post-processing on microstructural anisotropy and fatigue behaviour. Addit. Manuf. 2020, 36, 101433. [CrossRef]

4. Hopkinson, N.; Mumtaz, K. Top surface and side roughness of Inconel 625 parts processed using selective laser melting. Rapid Prototyp. J. 2009, 15, 96-103. [CrossRef]

5. Hopkinson, N.; Mumtaz, K. Selective laser melting of Inconel 625 using pulse shaping. Rapid Prototyp. J. 2010, 16, 248-257. [CrossRef]

6. Lee, H.; Lim, C.H.J.; Low, M.J.; Tham, N.; Murukeshan, V.M.; Kim, Y.-J. Lasers in additive manufacturing: A review. Int. J. Precis. Eng. Manuf.-Green Technol. 2017, 4, 307-322. [CrossRef]

7. Caprio, L.; Demir, A.G.; Previtali, B. Influence of pulsed and continuous wave emission on melting efficiency in selective laser melting. J. Mater. Process. Technol. 2019, 266, 429-441. [CrossRef]

8. Laitinen, V.; Piili, H.; Nyamekye, P.; Ullakko, K.; Salminen, A. Effect of process parameters on the formation of single track in pulsed laser powder bed fusion. Procedia Manuf. 2019, 36, 176-183. [CrossRef]

9. Biffi, C.A.; Fiocchi, J.; Bassani, P.; Tuissi, A. Continuous wave vs pulsed wave laser emission in selective laser melting of AlSi10Mg parts with industrial optimized process parameters: Microstructure and mechanical behaviour. Addit. Manuf. 2018, 24, 639-646. [CrossRef]

10. Chen, Z.W.; Guraya, T.; Singamneni, S.; Phan, M.A.L. Grain Growth During Keyhole Mode Pulsed Laser Powder Bed Fusion of IN738LC. JOM 2020, 72, 1074-1084. [CrossRef]

11. Han, Q.; Gu, H.; Soe, S.; Setchi, R.; Lacan, F.; Hill, J. Manufacturability of AlSi10Mg overhang structures fabricated by laser powder bed fusion. Mater. Design 2018, 160, 1080-1095. [CrossRef]

12. Calignano, F. Design optimization of supports for overhanging structures in aluminum and titanium alloys by selective laser melting. Mater. Design 2014, 64, 203-213. [CrossRef]

13. Chen, Z.; Wu, X.; Tomus, D.; Davies, C.H. Surface roughness of Selective Laser Melted Ti-6Al-4V alloy components. Addit. Manuf. 2018, 21, 91-103. [CrossRef]

14. Gong, H.; Rafi, K.; Gu, H.; Starr, T.; Stucker, B. Analysis of defect generation in Ti-6Al-4V parts made using powder bed fusion additive manufacturing processes. Addit. Manuf. 2014, 1-4, 87-98. [CrossRef]

15. Cui, C.; Hu, B.; Zhao, L.; Liu, S. Titanium alloy production technology, market prospects and industry development. Mater. Design 2011, 32, 1684-1691. [CrossRef]

16. Scharowsky, T. Grundlagenuntersuchungen zum Selektiven Elektronenstrahlschmelzen von TiAl6V4; FAU University Press: Erlangen, Germany, 2017; ISBN 978-3-96147-044-0.

17. Boley, C.D.; Mitchell, S.C.; Rubenchik, A.M.; Wu, S.S.Q. Metal powder absorptivity: Modeling and experiment. Appl. Opt. 2016, 55, 6496-6500. [CrossRef] [PubMed]

18. EOS GmbH_Electro Optical Systems. Material data sheet-EOS Titanium Ti64. Available online: https://www.eos.info/03 _system-related-assets/material-related-contents/metal-materials-and-examples/metal-material-datasheet/titan/ti64/eos_ ti64_9011-0014_9011-0039_m290_mds_11-17_en.pdf (accessed on 16 June 2021).

19. Wang, Y.; Kamath, C.; Voisin, T.; Li, Z. A processing diagram for high-density Ti-6Al-4V by selective laser melting. Rapid Prototyp. J. 2018, 24, 1469-1478. [CrossRef]

20. VDI Society Production and Logistics. Additive Manufacturing Processes, Rapid Manufacturing—Beam Melting of Metallic PartsQualification, Quality Assurance and Post Processing; Association of Engineers: Düsseldorf, Germany, 2013. 
21. Heinl, M.; Greiner, S.; Wudy, K.; Pobel, C.; Rasch, M.; Huber, F.; Papke, T.; Merklein, M.; Schmidt, M.; Körner, C.; et al. Measuring procedures for surface evaluation of additively manufactured powder bed-based polymer and metal parts. Meas. Sci. Technol. 2020, 31, 95202. [CrossRef]

22. DIN Fundamental Technical Standards Committee. Geometrical Product Specifications (GPS)—Surface Texture: Profile Method—Terms, Definitions and Surface Texture Parameters (ISO 4287:1997 + Cor 1:1998 + Cor 2:2005 + Amd 1:2009); German Version EN (ISO $4287: 1998$ + AC:2008 + A1:2009); Beuth Verlag GmbH: Berlin, Germany, 2010. 